Gut, 1986, 27, 363-369

\title{
Frequencies and cyclical pattern of the human sphincter of Oddi phasic activity
}

\author{
A TORSOLI, E CORAZZIARI, F I HABIB, E DE MASI, D BILIOTTI, \\ R MAZZARELLA, D GIUBILEI, G FEGIZ
}

From the Cattedra di Gastroenterologia and Clinica Chirurgica I, Università 'La Sapienza', Roma; Ospedale $S$ Agostino, Ostia; and Ospedale Civile, Tivoli, Italy.

SUMMARY Basal frequency of sphincter of Oddi phasic contractility has been repeatedly measured during endoscopic manometry and reported to range, in control subjects, from $(\mathrm{M} \pm \mathrm{SE}) 3.0 \pm 0.6$ to $7.5 \pm 0.7 \mathrm{c} / \mathrm{min}$. Recently, high frequency $(>8 \mathrm{c} / \mathrm{min})$ phasic contractions or absence of phasic activity were recorded in patients with postcholecystectomy or pancreatic complaints, possibly suggesting a sphincter of Oddi dysfunction. In the present study, sphincter of Oddi (biliary tract) phasic contractility was measured by perendoscopic manometry in 13 subjects without specific clinical symptoms of biliopancreatic disease and with a normal common bile and pancreatic duct at ERCP. Four T-tube patients with no evidence of common bile duct stones or papillary stenosis were studied for comparison (transductal sphincter of Oddi manometry). Basal frequency was found to range from 0 to $7 \mathrm{c} / \mathrm{min}(\mathrm{M} \pm \mathrm{SE}: 2 \cdot 99 \pm 0 \cdot 46)$ in perendoscopic manometry ( $85 \mathrm{~min}$ of recording time) and from 0 to $12 \mathrm{c} / \mathrm{min}(2 \cdot 0 \pm 0.3)$ in transductal manometry ( $2546 \mathrm{~min}$ of recording time). Long lasting transductal recordings also showed that frequency of activity derived from the sphincter area varied cyclically in close relation with the duodenal migrating motor complex. It is concluded that the sphincter of Oddi in man is likely to participate in the interdigestive gastrointestinal motor activity and that short perendoscopic recordings may not be representative of the overall sphincter of Oddi activity.

The sphincter of Oddi is a specialised and, to a large extent, embryologically independent ${ }^{1}$ muscular structure surrounding the terminal end of common bile and pancreatic duct. It determines a resistance to flow toward and from the duodenum and displays rapid closing and opening movements. As shown by cinefluorography opening is accompanied by an apparently free flux of ductal contrast medium into the duodenum. Closing movement begins with a ring like contraction at about half way of the sphincter, then the ducts obliterate and ampulla empties distally. Both movements appear to be relatively independent from duodenal motor activity. ${ }^{2} 3$

A quantitative evaluation of sphincter of Oddi motility is possible by intra-Oddian manometry, and the endoscopic cannulation of the papilla allows measurements to be made in intact subjects and in both the biliary and pancreatic tract of the sphincter.

\footnotetext{
Address for correspondence: Aldo Torsoli MD, Cattedra di Gastroenterologia, clo 2a Clinica Medica. Viale del Policlinico, (K)161 Roma, Italy. Received for publication 12 July 1985
}

Pull through manometry shows that a zone of raised resting pressure corresponds to the distal end of the ducts, possibly indicating a continuous local tonic activity. Superimposed on the resting pressure are phasic waves which appear either simultaneous or in temporal sequences suggesting anterograde or retrograde propagation.

Perendoscopic measurements include length and basal pressure of the sphincter, amplitude, duration, frequency, and propagation of phasic waves. Basal frequency was reported to range $(\mathrm{M} \pm \mathrm{SE})$ from $3.0 \pm 0.6$ to $7.5 \pm 0.7 \mathrm{c} / \mathrm{min}^{4-9}$ Frequencies higher than $8 \mathrm{c} / \mathrm{min}$ were recently recorded for several minutes in patients with postcholecystectomy symptoms and were proposed as an explanation for biliary dykinesia (tachyoddia). ${ }^{10}$ Periods of high frequencies, or the absence of phasic activity, have also been observed in patients with idiopathic relapsing pancreatitis and presumptive sphincter of Oddi dysfunction. ${ }^{11}$ Perendoscopic manometry, however, might not be representative of the overall sphincter motility as recordings are relatively short 
and possibly influenced by drugs used for premedication and the presence of the endoscope within the duodenum.

The aim of this study was therefore to further analyse basal frequencies of biliary sphincter of Oddi phasic activity. Perendoscopic manometric tracings from subjects without specific clinical symptoms of biliopancreatic disease, and with apparently normal biliary and pancreatic ducts at ERCP, were compared with more prolonged recording obtained by transductal manometry from patients with an external biliary drainage. ${ }^{12}$

\section{Methods}

\section{MANOMETRIC RECORDINGS}

A polyethylene triple lumen catheter, $200 \mathrm{~cm}$ in length, with an outer diameter of $1.7 \mathrm{~mm}$ and luminal diameters of $0.5 \mathrm{~mm}$ (Med. Techn. Inc. Watertown, Mass, USA) was used to record intraluminal pressures from the biliary tract. Each lumen ended with a $0.5 \mathrm{~mm}$ side hole and the three orifices were spaced $2 \mathrm{~mm}$ apart. The most distal orifice was $5 \mathrm{~mm}$ from the catheter tip. Starting from the most proximal orifice, the catheter was marked with eight black rings $2 \mathrm{~mm}$ apart.

Intraduodenal pressures were recorded by means of a single lumen polyvinyl catheter, with an outer diameter of $1.7 \mathrm{~mm}$ and an inner diameter of $0.8 \mathrm{~mm}$, which ended with a $0.8 \mathrm{~mm}$ side hole. A radioopaque marker placed distally to the side hole enabled the recording site at fluoroscopy to be localised. Each manometric catheter was continuously infused with bubble-free water at a rate of $0.5 \mathrm{ml} / \mathrm{min}$ by a minimally compliant hydraulic capillary infusion system (Arndorfer Inc, Greendale, Wisconsin, USA). Intraluminal pressures were transmitted to P23 Db Statham external transducers and then to a multichannel polygraph (either DR 8 Electronics for Medicine, White Plains, or R 511 A Beckman, Irvine, $\mathrm{Ca}$, USA) Paper ran at a constant rate throughout the recording periods: $2.5 \mathrm{~mm} / \mathrm{sec}$ during perendoscopic manometry and 2.5 or $1 \mathrm{~mm} / \mathrm{sec}$ during transductal manometry.

PROTOCOL OF THE STUDY

Perendoscopic manometry

Immediately before endoscopy all patients were sedated with diazepam $(10-20 \mathrm{mg}$ iv). At least 12 min after completion of the ERCP examination the triple lumen catheter was passed through the biopsy channel of a fiberoptic endoscope (Olympus JF 1T), the papilla recannulated and the common bile duct entered. The manometric catheter was introduced into the common bile duct to record intracholedochal pressure, and then withdrawn across the sphincter of Oddi in $2 \mathrm{~mm}$ step increments using the black marks on the catheter as a reference for measurement. During pressure recording the catheter position was monitored continuously through the endoscope by observing the position of the catheter marks relative to the papillary orifice. At the end of the manometric procedure a small amount of contrast medium (meglumine diatrizoate) was introduced through one of the lumens of the catheter to verify its correct position in the common bile duct.

Intraduodenal pressures were recorded by the single lumen catheter taped to the endoscope so that its recording orifice was $4 \mathrm{~mm}$ proximally to the biopsy channel opening.

\section{Transductal manometry}

Transductal manometry was done at least 15 days after surgery. The triple lumen manometric catheter was inserted, in one patient, through the T-tube and, in three patients, through the choledochocutaneous fistula remaining after T-tube extraction. The catheter was gently pushed through the sphincter of Oddi into the duodenum and then withdrawn across the sphincter of Oddi in $2 \mathrm{~mm}$ step increments to detect the sphincter high pressure zone. Insertion of the catheter into the duodenum and localisation of the recording side holes within the sphincter of Oddi were checked at fluoroscopy introducing contrast medium as needed through one of the three lumens. Exact location of the recording sites was also checked at fluoroscopy at the end of each recording period and whenever variation in the manometric record suggested dislocation of the catheter. Once the three recording sites were located within the sphincter the catheter was tightly anchored to skin. Recordings in basal conditions were done on separate days, three times in each patient. At the end of each recording session the tip of the catheter was withdrawn and left in the choledochus.

Intraduodenal pressures were recorded in two out of four patients by the single lumen catheter which was introduced transnasally with a small mercury bag attached at its distal end $15 \mathrm{~cm}$ distally to the recording orifice which, at fluoroscopy, was located in the second duodenal loop.

In both manometric approaches contrast medium has been used to visualise the common bile duct and/or to localise the manometric catheter and it cannot be excluded that instillation of contrast medium does not influence manometric recordings. Such a possible interference, if any, can be assumed to be scarcely relevant as by the time perendoscopic manometry is done the previously injected contrast medium has left the biliary tree and the small 
amount (1-3 ml) of contrast medium used to confirm positioning of the manometric catheter during manometry does not induce any pressure variation within the biliary tract as recorded simultaneously by the other two side holes.

ANALYSIS OF DATA

Sphincter of Oddi pressures were recorded as mmHg with duodenal pressure as zero reference. Pressure recordings were divided into one minute periods. Maximal basal midinspiratory pressure, mean amplitude and duration of phasic contractions were measured at the level of the middle recording orifice over each 1 minute period. Occasionally during transductal manometry sphincter of Oddi baseline recording dropped to zero. Basal pressure was considered to be zero if baseline equalled duodenal pressure in all three tracings, phasic waves were present and did not reflect simultaneous intraduodenal pressure variations and obvious artifacts could be excluded. A wave on sphincter of Oddi tracings was identified as a sphincteric contraction if at least $16 \mathrm{mmHg}$ high and appearing in close time relation with at least another wave in the remaining two tracings. A wave on duodenal tracing was identified as a duodenal contraction if at least $6 \mathrm{mmHg}$. These figures have been chosen because respiratory and movements artefacts seldom cause a pen deflection greater than 16 and $6 \mathrm{mmHg}$, in the sphincter of Oddi and duodenum, respectively and because in our previous studies the lower amplitude of sphincter of Oddi contractions was $16 \mathrm{mmHg}$ and the lower amplitude of duodenal contractions was $6 \mathrm{mmHg}$. Sphincter of Oddi and duodenal contractions were regarded to be associated if the entire or a part of the waves appeared simultaneously. The propagating pattern of sphincter of Oddi contractions were examined by analysing the three recording sites. Contractions were defined simultaneous if onset of the three waves appeared simultaneously; anterograde if onset of the waves appeared progres- sively delayed from the proximal to the distal recording sites; retrograde if onset of the three waves appeared progressively delayed from the distal to the proximal recording sites; mixed if the three waves did not follow any of the above definitions - for example, two simultaneous waves and one either retrograde or anterograde.

\section{PATIENTS}

Perendoscopic manometry was carried out in 13 subjects (six men, seven women, age range 25-61 years) undergoing ERCP examination for recurrent upper abdominal pain of unexplained origin and without biochemical evidence of biliary or pancreatic disease. Common bile duct did not exceed $8 \mathrm{~mm}$ in diameter and injected contrast medium flowed rapidly (in less than $6 \mathrm{~min}$ ) into the duodenum after retrograde cholangiography. None had been previously operated upon the biliary tree, pancreas or the digestive tract.

Transductal manometry was carried out in four additional patients (one man and three women, aged 56, 58, 71, and 76 years) in whom a transcholedochal T-tube was positioned at operation for acute cholecystitis and gall bladder stones (three patients) and acute pancreatitis (one patient). None

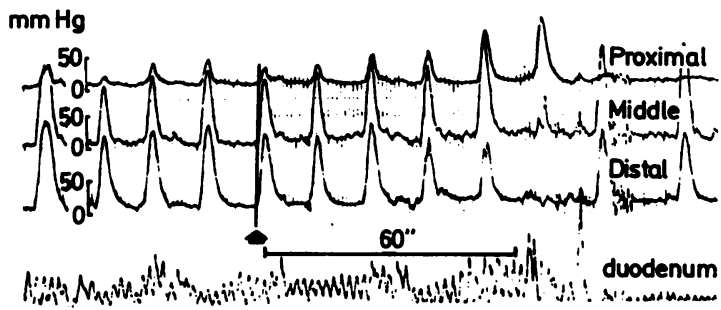

Fig. 1 Perendoscopic manometric recording from sphincter of Oddi and duodenum in fasting basal conditions: sphincter of Oddi phasic waves appearing simultaneously at the three recording sites. Calibration in $\mathrm{mmHg}$.

Table Manometric characteristic of sphincter of Oddi recording

\begin{tabular}{|c|c|c|c|c|c|}
\hline & & \multicolumn{2}{|c|}{ Perendoscopic } & \multicolumn{2}{|l|}{ Transductal } \\
\hline & & $M \pm S E$ & Range & $M \pm S E$ & Range \\
\hline $\begin{array}{l}\text { Sphincter of Oddi basal pressure } \\
\text { Sphincter of Oddi phasic activity }\end{array}$ & $(\mathrm{mmHg})$ & $13 \cdot 6 \pm 1 \cdot 3$ & $7 \cdot 5-25$ & $6 \cdot 4 \pm 1$ & $0-44$ \\
\hline $\begin{array}{l}\text { Amplitude } \\
\text { Duration }\end{array}$ & $\begin{array}{l}(\mathrm{mmHg}) \\
(\mathrm{sec})\end{array}$ & $\begin{array}{c}114 \cdot 3 \pm 10 \cdot 9 \\
6 \cdot 9 \pm 0 \cdot 5\end{array}$ & $\begin{array}{r}40-176 \\
3-11 \cdot 8\end{array}$ & $\begin{array}{c}51 \cdot 6 \pm 12 \\
3 \cdot 8 \pm 0 \cdot 5\end{array}$ & $\begin{array}{l}16-223 \\
3 \cdot 5-12\end{array}$ \\
\hline Propagation & (c/min) & & & & \\
\hline Anterograde & & $0 \cdot 2 \pm 0 \cdot 1$ & & $0.2 \pm 0.09$ & \\
\hline Retrograde & & $0 \cdot 3 \pm 0 \cdot 1$ & & $0.06 \pm 0.02$ & \\
\hline Simultaneous & & $1 \cdot 1 \pm 0 \cdot 4$ & & $1.22 \pm 0.67$ & \\
\hline Mixed & & $0 \cdot 3 \pm 0 \cdot 1$ & & $0 \cdot 3 \pm 0 \cdot 1$ & \\
\hline
\end{tabular}


of the patients had stones in the common bile duct or showed alterations at the distal part of the choledochus as judged at operation by cholangiography and easy passage of a soft $8 \mathrm{~F}$ catheter through the papilla. Enterohepatic circulation of bile was re-established by closing the external end of the T-tube at least one week before manometric examination.

This study was approved by the Ethical Committee of SIGE (Italian Society of Gastroenterology), and all patients gave informed consent.

\section{Results}

PERENDOSCOPIC MANOMETRY (Fig. 1)

Total recording time in basal conditions was 85 minutes (range in individual patients three to nine minutes). Length of sphincter of Oddi high resting pressure zone was $9.5 \pm 0.4 \mathrm{~mm}$ (range 7-13). Manometric characteristics of sphincter of Oddi are reported in the Table. Mean frequency of phasic contractions was $2 \cdot 99 \pm 0.4 \mathrm{c} / \mathrm{min}$ with a range from 0 to 7 . There was no phasic activity (zero frequency) during $15 \%$ of total recording time. Frequency distribution of phasic contractions is shown in Figure 2.

TRANSDUCTAL MANOMETRY (Fig. 3)

Total recording time in basal conditions was 2546 minutes (range for each recording session 39-686 minutes). Manometric characteristics of sphincter of Oddi are reported in the Table. Period of zero resting pressure could be detected in three patients and occurred during $16.6 \%$ of the total recording time. Mean frequency of phasic activity was $2 \cdot 0 \pm 0 \cdot 3$ $\mathrm{c} / \mathrm{min}$ with a range from a 0 to $12 \mathrm{c} / \mathrm{min}$. Zero frequency was recorded during $24.1 \%$ of total recording time and frequencies equal or greater than $8 \mathrm{c} / \mathrm{min}$ during $3 \cdot 1 \%$ of the time. Frequency distribution of phasic waves showed some skewness to the left (Fig. 2) with a peak at $0 \mathrm{c} / \mathrm{min}$.

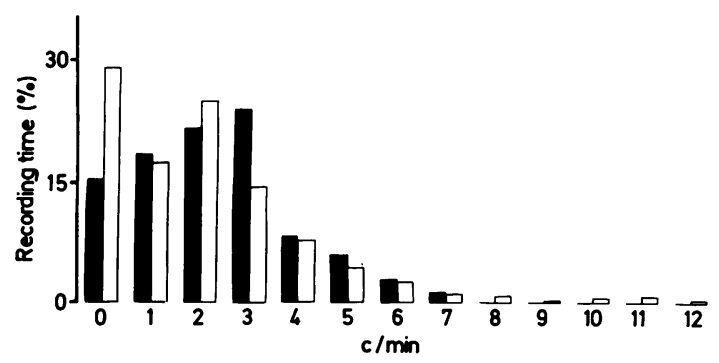

Fig. 2 Frequency distribution of phasic waves recorded by perendoscopic (black columns: 13 subjects) and transductal (empty columns: 4 pts) manometry in fasting basal conditions.

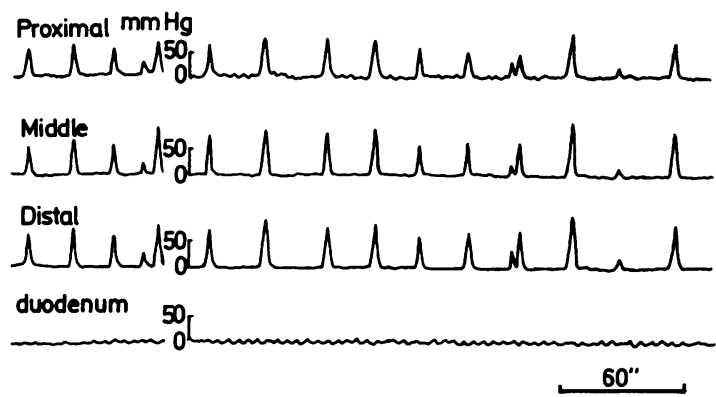

Fig. 3 Transductal manometric recording from sphincter of Oddi and duodenum in fasting basal conditions: sphincter of Oddi phasic waves appearing simultaneously at the three recording sites in the absence of duodenal contractions. Calibration in $\mathrm{mmHg}$.

Simultaneous sphincter of Oddi-duodenal long lasting recordings showed that sphincteric phasic activity varied cyclically over time paralleling the cyclical duodenal interdigestive motor complex (Fig. 4). Overall 10 phases at maximal, zero and intermediate frequency of contractions were recorded from the patients with transductal catheter. The phases with maximal frequency of phasic activity exhibited $9-12 \mathrm{c} / \mathrm{min}$, had a mean duration of $168 \mathrm{sec}$ (range 2-4 $\mathrm{min}$ ), and were followed by phases of zero frequency (mean duration $297 \mathrm{sec}$, range 1-7 $\mathrm{min}$ ). Phases with irregular and progressively increasing frequency of contractions (range $0-8 \mathrm{c} / \mathrm{min}$ ) ensued and had a mean duration of 76.5 min (range 33-111 min).

Overall two-thirds $(65 \cdot 1 \%)$ of sphincter of Oddi contractions appeared to be associated with duodenal contractions and, conversely, $34.9 \%$ were independent. During phase II association between sphincter of Oddi and duodenal contractions varied from 40 to $87 \%$. Maximal association, reaching $100 \%$, between sphincter of Oddi and duodenal contractions constantly occurred during the duodenal interdigestive phase III.

\section{Discussion}

Sphincter of Oddi is a complex of smooth muscle fibres showing both a tonic and phasic activity. Phasic activity is represented by contractions and relaxations corresponding to the cinefluorographic closing and opening movements of the sphincter area. Phasic contractions can be identified on manometric tracings as positive pressure waves either simultaneous or apparently propagating caudally or cranially. On occasion, anterograde or retrograde waves appear in a peristaltic-like pattern, however, because longitudinal Oddian fibres are not continuous around the circumference but condensed 

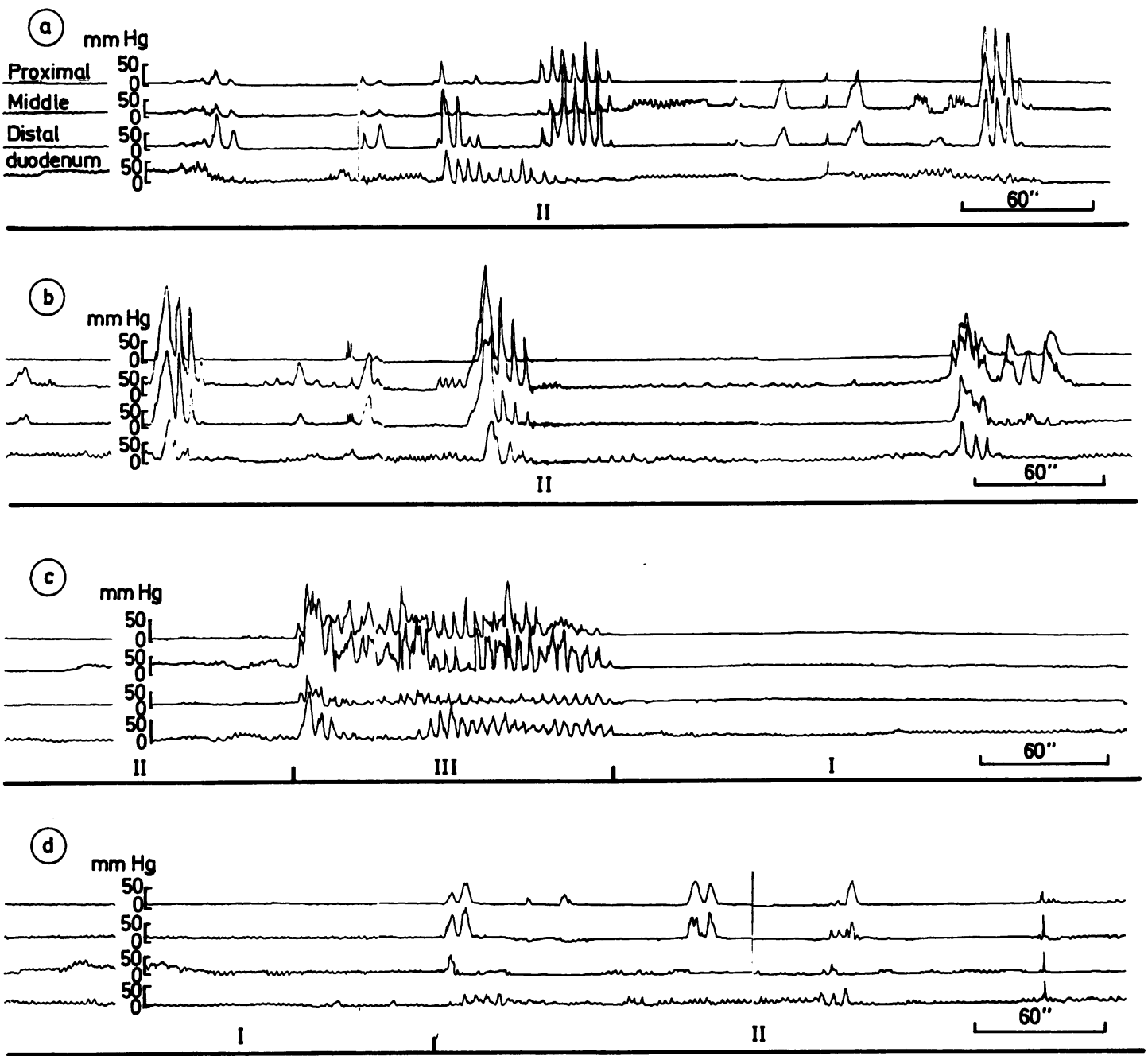

Fig. 4 Sphincter of Oddi and duodenal phases of the interdigestive migrating motor complex in a prolonged manometric session (transductal and duodenal manometry). The 35 min continuous recording shows phase II in $a, b$ and $d$, phase III in $c$, phase I in $c$ and $d$.

in two lateral fascicles, ${ }^{13}$ it seems unlikely that a true peristalsis takes place along the sphincter.

Sphincter of Oddi phasic contractions vary in frequency from subject to subject and also in the same subject, but do not significantly differ at various levels of the sphincter. ${ }^{14}$ In the present investigation, basal frequency ranged, at perendoscopic manometry, from 0 to $7 \mathrm{c} / \mathrm{min}$. Frequencies, equal or higher than $8 \mathrm{c} / \mathrm{min}$ or zero phasic activity were recorded for 0 and $15 \%$ of the time, respectively. Transductal manometry overcomes some of the limitations of perendoscopic approach. Sphincter of Oddi recordings can be prolonged (hours), there is neither premedication nor the endoscope in the duodenum. Although possible in a restricted population and corresponding to the unphysiological situation of recording from a bile duct which has been operated upon and which has access through an abnormal route, transductal manometry provided overall motor patterns comparable with those of perendoscopic manometry. Phasic wave frequency, however, ranged from 0 to $12 \mathrm{c} / \mathrm{min}$. Mean wave amplitude was smaller and mean duration shorter, although the range values of transductal manometry included those derived from perendoscopic manometry. Waves occurred some- 
times at an apparently regular time interval (Fig. 2), in other instances as short bursts of repetitive contractions (Fig. 4). No definite explanation can be given for these discrepancies, although the different recording approach, a possible sampling error among the limited number of patients investigated and the different mean age of the two groups could be taken into account.

This study shows that by means of prolonged transductal manometry it is possible to detect short periods of either rapid phasic contractions or no phasic activity due to the interdigestive cyclical changes in sphincter of Oddi frequency and which are rarely seen during short ERCP recordings. Accordingly, perendoscopic measurements should not be considered representative of the overall sphincter motility, but only of the activity phase during which manometry takes place. Transductal manometry also confirmed the relative independence of sphincter of Oddi phasic motility in man, as in the $\operatorname{dog},{ }^{15}$ and showed that this motility is submitted to cyclical changes apparently related to the various phases of the duodenal interdigestive migrating motor complex. Maximal frequencies $(10-12 \mathrm{c} / \mathrm{min})$ recorded from the sphincter of Oddi area coincided with phase III and no activity coincided with phase I of the duodenal interdigestive migrating motor complex. A varying number of autonomous sphincter of Oddi contractions were observed during duodenal phase I and II whereas in phase III sphincter of Oddi and duodenal contractions were closely associated. This close association raises the question whether sphincter of Oddi has its own pacemaker at the same frequency of the duodenum or its movements are paced by a duodenal pacemaker. In the latter situation, sphincter of Oddi $10-12 \mathrm{c} / \mathrm{min}$ phasic waves might simply reflect contraction of the duodenal muscle surrounding the papilla.

Experiments in rabbits provided evidence of independent pacemakers in the sphincter of Oddi and duodenum. ${ }^{16}$ In the opossum ${ }^{17}$ sphincter of Oddi spike burst activity showed a cyclic interdigestive pattern similar to that of the stomach and small bowel. Spike burst frequency of sphincter of Oddi and duodenum coincided during maximal motor activity but not during duodenal quiescence, when sphincter of Oddi bursts could still be recorded. In man, however, this problem deserves further study.

The cyclical pattern of sphincter of Oddi phasic activity suggests that the sphincteric activity is adjusted to deal with the cyclically varying flow of bile and pancreatic juice into the duodenum. In fact it is known ${ }^{18}$ that bile flow fluctuates over time (it increases progressively from phase I to phase III of the duodenal interdigestive migrating motor com- plex and then decreases markedly during phase III) and recent observations in $\operatorname{dog}^{15}$ seem to indicate that such phasic changes might play a major role in regulating delivery of bile and pancreatic juice into the duodenum.

This work was supported in part by the CNR, grant no. CT 82.02112.04. A preliminary communication of this work appeared as an abstract ${ }^{19}$ and was presented as poster at the AGA Meeting, New Orleans, Louisiana, May 1984.

\section{References}

1 Schwegler RA, Boyden EA. The development of the pars intestinalis of the common bile duct in the human fetus with special reference to the origin of ampulla of Vater and the sphincter of Oddi. 2: The early development of the musculus proprius. Anat Rec 1937; 68: 17-40.

2 Torsoli A, Ramorino ML, Palagi L. Colagrande C, Baschieri I, Ribotta G. Observations roentgencinematographiques et electroma nometriques sur la motilité des voies biliares. Sem Hôp 1961; 37: 790-802.

3 Torsoli A, Ramorino ML, Alessandrini A. Motility of the biliary tract. Rend RR Gastroenterol 1970); 2: $67-80$.

4 Corazziari E, De Masi E, Gatti V et al. Caerulein and sphincter of Oddi pressure activity. Ital J Gastroenterol 1982; 14: 239-41.

5 Geenen JE, Morgan WJ, Dodds WJ, Stewart ET, Arndorfer RC. Intraluminal pressure recordings from the human sphincter of Oddi. Gastroenterology 1980; 78: $317-24$.

6 Toouli J, Geenen JE, Hogan WJ, Dodds WJ, Arndorfer RC. Sphincter of Oddi motor activity: a comparison between patients with common bile-duct stones and controls. Gastroenterology 1982; 82: 111-7.

7 Carr-Locke DL, Gregg JA. Endoscopic manometry of pancreatic and biliary sphincter zones in man: basal results in healthy volunteers. Dig Dis Sci 1981; 26: $7-15$.

8 Csendes A, Kruse A, Funch-Jensen P, Øster MJ, Ørnsholt J, Amdrup E. Pressure measurements in the biliary and pancreatic duct system in controls and in patients with gall stones, previous cholecystectomy, or common bile duct stones. Gastroenterology 1979; 77: 1203-10.

9 De Masi E, Corazziari E. Habib FI, Fontana B, Gatti V, Fegiz G, Torsoli A. Manometric study of the sphincter of Oddi in patients with and without common bile duct stones. Gut 1984; 25: 275-8.

10 Hogan WJ, Geenen JE, Venu R, Dodds WJ, Helm J, Toouli J. Abnormally rapid phasic contractions of the human sphincter of Oddi (tachyoddia). Gastroenterology 1984; 86: 1289.

11 Toouli J, Roberts-Thompson I, Dent J. Sphincter of Oddi (SO) manometric profile in patients with idiopathic relapsing pancreatitis. Gastroenterology 1984; 86: 1283 
12 Torsoli A, Corazziari E, Habib FI, et al. Prolonged transductal manometry of the sphincter of Oddi. Ital J Gastroenterol 1985; 17: 35-7.

13 Boyden EA. The sphincter of Oddi in man and certain representative mammals. Surgery 1937; 1: 25-37.

14 De Masi E, Corazziari E, Gatti V et al. Perendoscopic manometry of the sphincter of Oddi. Surg Gastroenterol 1982; 1: 335-9.

15 Scott RB, Strasberg SM, EL-Sharkawy TY, Diamant NE. Fasting canine biliary secretion and the sphincter of Oddi. Gastroenterology 1984; 87: 793-804.

16 Sarles JC, Bidart JM, Devaux MA, Echinard C, Castagnini A. Actions of cholecystokinin and caerulein on the rabbit sphincter of Oddi. Digestion 1976; 14: 415-23.

17 Honda R, Toouli J, Dodds WJ, Sarna S, Hogan WJ, Itoh Z. Relationship of sphincter of Oddi spike bursts to gastrointestinal myoelectric activity in conscious opossum. J Clin Invest 1982; 69: 770-8.

18 Vantrappen GR, Peeters TL, Janssens J. The secretory component of the interdigestive migrating motor complex in man. Scand J Gastroenterol 1979; 14: 663-4.

19 Corazziari E, Torsoli A, De Masi E et al. Frequency distribution of human sphincter of Oddi phasic activity. Gastroenterology 1984; 86: 1054. 